Article

\title{
Theoretical Guidance on Evacuation Decisions after a Big Nuclear Accident under the Assumption That Evacuation Is Desirable ${ }^{\dagger}$
}

\author{
Yaling Deng ${ }^{1}$, Shuliang Zou ${ }^{2, *}$ and Daming You ${ }^{1}$ \\ 1 School of Business, Central South University, Changcha 410083, China; dengyl@csu.edu.cn (Y.D.); \\ youdaming2001@163.com (D.Y.) \\ 2 School of Management, University of South China, Hengyang 421001, China \\ * Correspondence: zoushuliang@usc.edu.cn \\ $+\quad$ International Conference on Nuclear Safety, Nuclear Emergency and Nuclear Security-Nuclear Energy \\ Knowledge Management of the BRICS Countries, ICNNN/NEKM, Hengyang, China, 3-6 December 2017.
}

Received: 10 August 2018; Accepted: 28 August 2018; Published: 30 August 2018

\begin{abstract}
The development of nuclear power is a major measure for implementing energy-saving and emission reduction strategies all over the world. For a long time, the hazards of nuclear accidents have been obstacles to the development of nuclear power. Temporary evacuation is the fastest and most effective emergency measure to ensure the safety of residents in a short period of time after a nuclear accident. Numerous nuclear accident emergency management personnel make judgments based on personal work experience and subjective awareness when formulating a nuclear accident emergency evacuation plan. How to make a scientific and reasonable decision on the emergency evacuation of nuclear accidents in the shortest time is a common problem faced by many emergency departments when a nuclear accident occurs. In a complex and ever-changing radiation environment, how to maximize the use of limited information and make decisions quickly in an uncertain environment is a core issue that effectively reduces the risk of nuclear accidents. This paper constructs a set of assessment system of nuclear accident emergency evacuation plan selection based on the characteristics of nuclear accident emergencies under uncertain environmental conditions. It uses triangular fuzzy language to describe nuclear accident emergency evacuation decision plans and the weighting of relevant factors. Additionally, the K-means clustering method is used to calculate the weight of experts, which reduces the influence of subjective factors considered by decision makers. Finally, a decision model for emergency evacuation of nuclear accidents is constructed based on the TOPSIS decision model.
\end{abstract}

Keywords: triangular fuzzy language; TOPSIS decision method; nuclear accident; emergency evacuation

\section{Introduction}

Speeding up the reform of ecological civilization to achieve green development will be an arduous task for China in the future. Nuclear power, as a clean, safe, and efficient energy resource, is of great significance in the construction of beautiful China. After more than 30 years of development, the Chinese nuclear power industry has made remarkable achievements in that 36 nuclear power units are now running and all of them have been operating safely with 'zero' accidents, which is due to the excellent nuclear security guarantee work in the field of nuclear safety. Nuclear security is a complex and huge project, challenged at all times by uncontrollable factors, such as equipment failure, natural disasters, human error, and other factors causing nuclear accidents. A nuclear accident is one of the most feared hazards to all countries in the world. The various stages following a nuclear accident are the planning phase, response phase, post-release, and recovery phase [1]. In order to reduce the 
radiological damage to the surrounding residents caused by nuclear accidents, emergency measures including sheltering, evacuation, restrictions on the sale of locally-grown food, and relocation should be considered [2]. Evacuation refers to the transfer of residents to safe areas for several days in the early stage of a post-nuclear accident situation until the radiation dose is stable and acceptable to humans. As a nuclear accident is a low-probability event in reality, there is an extreme lack of experience in accurately assessing the hazards of nuclear accidents and effectively formulating plans for the emergency evacuation of nuclear accidents, which has led to organizational confusion and ineffective management in the event of a nuclear accident [3]. Thomas has pointed out that the relocation of lots of people was not the best and most reasonable solution from the perspective of cost and risk in the Chernobyl and the Fukushima Daiichi accidents, and an improved decision support mechanism should be constructed based on the radionuclide measurement and modelling systems [4]. Waddington et al. have assessed the relocation measures of Chernobyl and the Fukushima Daiichi accidents using the J-value, concluding that the relocation measures taken in Fukushima Daiichi were unreasonable, and that the relocation measures following the Chernobyl accident were only reasonable for between $9 \%$ and $22 \%$ of the individuals, who were ultimately relocated [5]. The temporary evacuation of people is a logical emergency measure in many major nuclear accidents until such a point that the experts are able to determine the extent of radioactivity [4]. However, how to determine the number of evacuees, evacuation routes, and evacuation ranges based on considerations of safety, economy, and feasibility is a difficult problem. Policy makers are required to formulate a protective action plan quickly and efficiently based on a prediction of the status of the nuclear facility and the surrounding environment in a nuclear accident [6]. In many nuclear emergency incidents, disasters are handled by an 'event commander', who may accept opinions from decision experts in various fields, but who will eventually make the final decision based on his or her own judgment. Therefore, the commanding officer's decision-making ability in an emergency situation is very important.

The emergency evacuation of nuclear accidents is a complicated task [7]. Liu studied the early emergency of a nuclear accident and used a decision-making method to construct a decision-making model [8]. Zhixin et al. used the utility function to establish the multiple attribute decision-making model, which was utilized to choose the best evacuation plan [9]. On one hand, the decision makers' decision on when to evacuate and what route to choose to evacuate is a multiple attribute decision-making problem, which is influenced by many factors [10]. The development of a nuclear accident emergency evacuation plan is a complex group decision problem that is affected by the characteristics of accidents, decision makers, and the availability of limited resources [3]. In a nuclear accident emergency plan, it is very important to effectively control the various parameters related to the accident [11]. Urbanik proposed that evacuation time is the sum of decision time, notification time, preparation time, and response time [12]. Moeller et al. studied the influencing factors of emergency evacuation time from 11 aspects: emergency planning area size, evacuation demand and traffic capacity, etc. Based on the traffic flow theory, the Northwest Pacific National Laboratory has adopted a more realistic hypothesis to develop the CLEAR model, applying the model to the Beaver Valley nuclear power plant in the United States [13]. Tseng and Chang constructed a decision model for nuclear emergency preparedness and corresponding risk assessment, pointing out that radionuclide transport had great potential hazards [14]. Srinivas et al. established a nuclear accident emergency response decision model based on wind direction and radiation dose [15]. Silva et al. pointed out that a nuclear accident is a very complicated incident, and that emergency decision making and planning must fully consider the influence of geographical and spatial factors, such as rainfall, wind speed, and population density, to establish a decision system [16]. Wang et al. carried out a simulation of the emergency evacuation time of a nuclear accident from seven aspects such as vehicle loading, vehicle movement, vehicle arrival and waiting, and intersection processing [17]. There are common multi-attribute decision methods including TOPSIS, VIKOR, PROMETHEE, ELECTRE, and other methods. Halkos and Tzeremes used the method of DEA to evaluate the financial performance of the manufacturing industry as a multi-criteria decision-making problem [18]. Yan et al. constructed a series 
of indicators to evaluate the performance of a coal enterprise using a method of GRD-TOPSIS [19]. Safaei Ghadikolaei et al. proposed that the competitiveness of a company is partly reflected by financial performance, then used FAHP and VIKOR methods to evaluate the competitiveness of a company [20]. Chakraborty et al. used the PROMETHEE-GIS method to evaluate educational performance [21]. Hoseinpour et al. proposed that the calculation process of the TOPSIS method is relatively simple and fast, having a systematic procedure [22]. TOPSIS allows for indicators to be inter-correlated, which is more in line with actual real life situation and represents a unique advantage over other multi-attribute decision methods [23]; Funda Samanlioglu et al. proposed that the method of TOPSIS has the advantage of comprehensibility, good computational efficiency, and rationality, and applied the integration of TOPSIS and FHP to the IT personnel selection [24].

On the other hand, the emergency evacuation decision for a nuclear accident is a task that requires the decision makers to comprehensively consider various aspects to select the optimal evacuation plan in an uncertain environment. The difficulty with emergency evacuations is that the information related to radiation dose and the surrounding environment may be incomplete and cannot be subscribed completely in the short term, moreover, some information changes with time and space [25]. There is a lot of uncertainty in the early stages of a nuclear accident; the decision-maker only knows that nuclear reactor failure is the cause of the accident but cannot fully grasp the detailed information about the current state and potential hazard of the accident [26]. Marjan Malešič also has mentioned that the implementation of the nuclear accident emergency evacuation plan faces many uncertainties. In the event of an emergency evacuation, the timeliness and effectiveness of the evacuation cannot be guaranteed due to the lack of a sufficient theoretical basis [27]. While, fuzzy set theory is widely used in decision making with fuzzy and uncertain information, which uses linguistic variables, fuzzy sets, and membership functions to measure qualitative and quantitative indicators [28]. Bier has proposed that the fuzzy set theory is suitable for processing boundary-blurred data sets and does not require that the data be accurate [29]. Chai et al. have pointed out that the combination of fuzzy set theory and multi-attribute decision-making can effectively deal with the uncertainty in the supplier selection process, which uses appropriate language to deal with inaccurate standards in qualitative and quantitative indicators [30]. Xinjing used interval analytic hierarchy process to establish a multi-objective decision model to sort the nuclear accident decision-making scheme, which effectively solves the uncertainty and fuzziness of expert experience judgment in nuclear accident emergency decision-making [31]. Boran et al. have proposed that the criteria information given by experts cannot be expressed by crisp data precisely in supplier selection, and intuitionistic fuzzy sets can make up for this defect under uncertain environment [32]. Wu and Chen built a model to calculate the overall preference value of each alternative based on fuzzy language under the condition that the attribute weight information is completely unknown [33].

Fuzzy TOPSIS is the extension of the TOPSIS method, which is widely applied to deal with data fuzziness with linguistic variables [34]. Liu and Wei employed Fuzzy-TOPSIS method to evaluate the risk to electric vehicles from charging infrastructure Public-Private-Partnership projects, ranking the alternative projects [35]. Han and Trimi used the Fuzzy-TOPSIS method to evaluate the performance of the three logistics companies on a social networking platform [36].

However, the weight of the evaluation indicators and experts is the core part of multi-attribute decision-making. The common methods for determining weight include Delphi m, Analytic Hierarchy Process [37], information entropy [38], and K-means cluster analysis [39]. The K-means cluster analysis method has the advantages of low computational complexity, high processing data efficiency, and generated cluster clustering that does not overlap [40]. Ray and Turi used K-means cluster analysis to classify data between groups and within groups and applied it to color image segmentation [41]. Wang and Shao used K-means to classify the fault feature information of a planetary gearbox in order to divide the planetary gearbox's health status into different levels [42]. Desarbo et al. [43] first applied K-means to weight calculations. Since then, De Soete [44] has successively studied this method in 
conjunction with the calculation of weightings, reducing the influence of subjective factors in the decision-making process and improving the scientific nature of the decision-making model.

In summary, the decision for the emergency evacuation of nuclear accidents is optimal solution selection under an uncertain environment for a commander faced with multiple options, which is an incomplete information multi-attribute decision problem. Existing research is less concerned with how the commander chooses the best option under incomplete information conditions. Few people pay attention to the problem of determining the weight of decision-making experts, whose weight determines the importance of the information and has a significant impact on the commander's decision-making. This study is based on the following three assumptions:

Hypothesis 1. A portion of the individuals in the area surrounding a nuclear accident should be evacuated temporarily until the radioactive release is confirmed to be safe.

Hypothesis 2. In the group decision-making process, a commander is responsible for organizing the experts to state their opinions, and finally collecting the evaluation of the alternatives by the experts through questionnaires, which are described by fuzzy language.

This article mainly focuses on how the commander can quickly and effectively integrate the information of multiple experts during the process of making an emergency evacuation decision for a nuclear accident. Firstly, an evaluation index system for nuclear accident emergency evacuation has been established based on the relevant research at home and abroad. In addition to considering the characteristics of a nuclear accident emergency, experts use triangular fuzzy language to evaluate the attributes of alternatives. In addition, this article considers the differences in the sources of different experts and tries to use cluster analysis to determine expert weight in order to optimize the traditional TOPSIS decision-making method. Finally, an example is applied to the model.

\section{Evaluation Index of Nuclear Accident Emergency Evacuation}

The emergency evacuation of nuclear accidents is a planned, organized, and early warning action to transfer people who may be affected by radiation to a safe area after a nuclear accident for a short term. In the process of evacuation, not only should the influence of radiation dose in the accident area be considered, the possible problems and consequences stemming from the implementation of the evacuation plan also cannot be ignored. In order to assess the emergency evacuation capacity of nuclear power plants, it is necessary to make a dynamic assessment of the evacuation efficiency under different scenarios and with adequate considerations of the potential changes resulting from various influencing factors around the nuclear power plant. Emergency evacuation is affected by the size of an emergency planning area, evacuation demand, traffic capacity, unfavorable weather conditions, traffic capacity, road traffic, travel time and confirmation time, power plant reverse road, and reception center location [45].

Emergency planning area size: The division of an emergency planning area in China usually places the nuclear power plant as the center point, a radius of $7 \sim 10 \mathrm{~km}$ is divided into the plume emergency plan area, and a radius of $30 \sim 50 \mathrm{~km}$ range is divided into the food emergency plan area. The scope of an emergency planning area directly affects the response range of the nuclear accident emergency evacuation.

Evacuation demand: Evacuation demand refers to the population and transportation-related demands for evacuation in an emergency planning area. Population demand is affected by the distribution of the resident population, floating population, and special population in the emergency evacuation area. The demand of vehicles is affected by the number of private cars and the carrying rate of residents in the emergency planning area.

Road traffic: Different traffic characteristics have different effects on emergency evacuation time, these features mainly include: system topology, system topology; the characteristics of the road; 
the current traffic capacity; traffic control quantity; installation and operation of the lane width of pavement, roads, and bridges; limit position and width of road lanes; channel intersection queue capacity; speed limitations, etc.

Unfavorable weather conditions: Different weather conditions (rain, snow, etc.) will significantly reduce the load capacity and transport speed and extend the emergency evacuation time. Measures such as the continuous monitoring of congested road sections in the area, remote control of intersections, and the removal of traffic jams by roadside service vehicles can mitigate adverse impacts. Different weather conditions should be considered according to the actual conditions of the site, while it should also be evaluated whether bad weather will require a redirecting of the evacuation route or cause the road capacity to reduce.

Traffic capacity: The traffic capacity of a road during an emergency evacuation scenario will be different from the normal traffic to a certain extent. The evacuation vehicle proportion, the probability of a road accident, and the probability of road damage are the all important factors affecting the traffic capacity.

The time spent before leaving and running time: The former is the time between the evacuation notice arrival and the time at which point a vehicle is evacuated. The latter is the evacuation time of the vehicle on the road network after the vehicle gets on the train.

Reverse road of power plant: When an emergency planning area is waiting for a large number of people to evacuate, it usually will adopt a group evacuation strategy. At this point, the evacuation of vehicles requires multiple trips on the evacuation route, and the convenience of the reverse road(s) directly affects the evacuation time.

\section{Model Building}

There are a set of multi-attribute decision making schemes, represented as $X=\left\{x_{1}, x_{2}, \ldots x_{n}\right\}$, where $x_{i}$ represents the $i$ th decision scheme. Each scheme has $n$ attributes, represented as $G=\left\{G_{1}, G_{2}, \ldots, G_{m}\right\}$, where $G_{j}$ denotes the $j$ th index. The emergency decision making process needs $k$ experts, represented by $D=\left(\begin{array}{lllll}D_{1} & D_{2} & D_{3} & \cdots & D_{k}\end{array}\right)$, where $D_{q}$ represents the $q$ th decision maker. In a nuclear accident emergency evacuation decision, a lot of information cannot be described accurately in a short time, as such, decision experts tend to use fuzzy language to evaluate the weights and values of attribute. Therefore, it is reasonable to represent attribute weight and attribute value in triangular fuzzy number form, which are respectively represented as $\widetilde{w}_{j}^{q}=\left(\begin{array}{llll}\widetilde{w}_{1}^{q} & \widetilde{w}_{2}^{q} & \cdots & \widetilde{w}_{m}^{q}\end{array}\right)$ and $\widetilde{u}_{i j}^{q}=\left(\begin{array}{lllll}\widetilde{u}_{i 1}^{q} & \widetilde{u}_{i 2}^{q} & \cdots & \widetilde{u}_{i m}^{q}\end{array}\right)$, where $\widetilde{w}_{m}^{q}$ expresses the weight of the $j$ th attribute given by the $q$ th decision maker, $\widetilde{u}_{i m}^{q}$ is the score of the $j$ th attribute of the $i$ th decision scheme given by the $q$ th decision maker, thus forming the index weight matrix $W=\left(\widetilde{w}_{j}^{q}\right)_{m \times k}$ and decision matrix $\widetilde{U}^{q}=\left(\widetilde{u}_{i j}^{q}\right)_{n \times m}$.

\subsection{Algebraic Operations WITH Fuzzy Numbers}

Definition 1. Operations of triangular fuzzy numbers [46].

Triangular fuzzy numbers are represented as $a=\left(a^{L}, a^{M}, a^{U}\right)$ and $b=\left(b^{L}, b^{M}, b^{U}\right)$, where $0<a^{L} \leq$ $a^{M} \leq a^{U}$, the membership function, can be expressed as:

$$
\left\{\begin{array}{c}
\left(x-a^{L}\right) /\left(a^{M}-a^{L}\right), a^{L} \leq x \leq a^{M} \\
\left(x-a^{U}\right) /\left(a^{M}-a^{U}\right), a^{M} \leq x \leq a^{U} \\
0,0<x \leq a^{L} \quad \text { or } \quad x \geq a^{U}
\end{array}\right.
$$

The main algebraic operations are presented as follows:

(1) Additive operation: $a+b=\left[a^{L}+b^{L}, a^{M}+b^{M}, a^{U}+b^{U}\right]$

(2) Multiplication operation: $a b=\left[a^{L} b^{L}, a^{M} b^{M}, a^{U} b^{U}\right]$

(3) Division operation: $\frac{a}{b}=\left[\frac{a^{L}}{b^{L}}, \frac{a^{M}}{b^{M}}, \frac{a^{U}}{b^{L}}\right]$ 
(4) Inverse of a triangular fuzzy number: $\frac{1}{a}=\left[\frac{1}{a^{L}}, \frac{1}{a^{M}}, \frac{1}{a^{U}}\right]$

(5) Number multiplication operation: $\lambda a=\left[\lambda a^{L}, \lambda a^{M}, \lambda a^{U}\right]$.

Definition 2 [46]. The two triangular fuzzy number vectors are represented as $a=\left(a^{L}, a^{M}, a^{U}\right)$ and $b=\left(b^{L}, b^{M}, b^{U}\right)$, then the distance between $\widetilde{a}$ and $\widetilde{b}$ is defined as: $d_{(\widetilde{a}, \widetilde{b})}=\sqrt{\frac{1}{3}\left[\left(a^{L}-b^{L}\right)^{2}+\left(a^{M}-b^{M}\right)^{2}+\left(a^{U}-b^{U}\right)^{2}\right]}$.

\subsection{Fuzzy-TOPSIS}

The TOPSIS method is a decision method based on the relative closeness of positive and negative ideal solutions, the calculation steps for this method are as follows:

(1) $\quad \widetilde{w}_{j}^{q}=\left(\begin{array}{cccc}\widetilde{w}_{1}^{q} & \widetilde{w}_{2}^{q} & \ldots & \widetilde{w}_{m}^{q}\end{array}\right)$ is the attribute value vector and $\widetilde{u}_{i j}^{q}=\left(\begin{array}{llll}\widetilde{u}_{i 1}^{q} & \widetilde{u}_{i 2}^{q} & \ldots & \widetilde{u}_{i m}^{q}\end{array}\right)$ is the attribute weight vector of L experts in various fields, which are explained by triangular fuzzy language shown in Table 1 to evaluate the alternative solutions [47].

Table 1. The assessment matrix of emergency plan.

\begin{tabular}{ccc}
\hline Grade I & Evaluation Value & Triangular Fuzzy Number \\
\hline 1 & Very poor & $(0,0,0.25)$ \\
2 & Poor & $(0,0,0.5)$ \\
3 & General & $(0.25,0.5,0.75)$ \\
4 & Good & $(0.5,0.75,1)$ \\
5 & Very good & $(0.75,1,1)$ \\
\hline
\end{tabular}

(2) Determine the weight of decision makers

The commander cannot fully grasp the information of each expert and it is difficult to judge the importance of experts accurately according to only the subjective judgment of the commander in a short period of time. In this study, the expert weight consists of two parts, one of which is $\lambda=\left(\lambda^{1}, \lambda^{2}, \ldots \lambda^{q} \ldots \lambda^{L}\right)$, evaluated by the commander according the experts' work experience, the other is $e=\left(\mathrm{e}_{j}^{q}\right)_{\mathrm{m} \times \mathrm{L}}$, calculated on the basis of a cluster analysis of expert evaluation based on $\mathrm{K}$-means cluster analysis, which requires the commander to divide the decision-making experts into $\mathrm{k}$-classes based on the most important attributes. The criterion of clustering is the degree of proximity between two preference vectors. The experts who are in the same category have the same preferences, so the weight of experts in the same class are the same. The size of clusters determines the weight of members [42]. It is assumed that the preference vector of the $q$ experts to the decision value of the $i$ th decision scheme is the following:

$V_{i}^{q}$ is the evaluation value matrix for the $i$ th scheme evaluated by $q$ th expert, $V_{i}^{q}=\left(\begin{array}{llll}v_{i 1}^{q} & v_{i 2}^{q} & \ldots & v_{i m}^{q}\end{array}\right) . \quad V_{i}$ is the evaluation value matrix for the $i$ th scheme given by all experts. $V_{i}=\left[\begin{array}{cccc}v_{i 1}^{1} & v_{i 2}^{1} & \cdots & v_{i m}^{1} \\ v_{i 1}^{2} & v_{i 2}^{2} & \cdots & v_{i m}^{2} \\ \vdots & \vdots & \cdots & \vdots \\ v_{i 1}^{k} & v_{i 2}^{k} & \cdots & v_{i m}^{k}\end{array}\right] V$ is the evaluation value matrix for all schemes, $V=\left(v_{i j}^{q}\right)_{\mathrm{n} \times \mathrm{m}}$. The cluster preference structure was formed by the cluster analysis of $V_{i j} . V_{i j}$ is gathered into $k$ classes, which is the number of classes that the commander divides experts into based on specific attributes. $K$ clusters are described as follows, $C_{i j}^{1} \quad C_{i j}^{2} \ldots C_{i j}^{K}$. The number of vectors contained in $C_{i j}^{k}$ is $n_{i j}^{k}$, $\sum_{k=1}^{K} n_{i j}^{k}=L, \quad 1 \leq K \leq L$, [48]. $e_{i j}^{q}$ is the weight of the $q$ th expert obtained by clustering the evaluation value of the $j$ th attribute value of the $i$ th scheme. $q=1, \ldots, L ; k=1, \ldots, K$. The weight matrix of experts is $e=\left(\mathrm{e}_{j}^{q}\right)_{\mathrm{m} \times \mathrm{L}}$. 
Clustering all of the experts' evaluation values in the $i$ th scheme is described as follows [49]:

Step 1: the initial cluster centers are randomly assigned from $C_{i j}^{1}$ to $C_{i j}^{K}$

Step 2: repeat

Step 3: for $q=1$ to $k$

Step 4: the triangular fuzzy distance of each non-center point $c_{i j}^{l}$ to cluster center is calculated. In distance $\mathrm{D}$, the smallest data point $v_{i j}^{q}$ is assigned to $c_{i j}^{l}$

Step 5: end for

Step 6: for $j=1$ to $K$ do

Step 7: recalculate the center $c_{i j}^{l}$ of the cluster $C_{i j}^{l}$

Step 8: end for

Step 9: the cluster center will not change anymore

Step 10: return C

\section{(3) Normalization of Attribute Values}

The evaluation indexes are usually divided into benefit type and cost type, which are represented by $I_{j},(j=1,2) ; I_{1}$ represents the benefit type and $I_{2}$ represents the cost type. In order to eliminate the influence of different physical dimensions on the attribute values, the following formula is used to standardize the triangular fuzzy numbers, which is applied in the research of numerous scholars, such as $\mathrm{Xu}$ [50], Wan [51], and so on. The norm of the vector is represented as \|\|$, x_{i j}^{q}=\frac{u_{i j}^{q}}{\left\|u_{i j}^{q}\right\|^{\prime}}, j \in I_{1}, i \in N$, $x_{i j}^{q}=\frac{\left(\frac{1}{u_{i j}^{q}}\right)}{\left\|\frac{1}{u_{i j}^{q}}\right\|}, j \in I_{2}, i \in N$, where $\left\|u_{i j}^{q}\right\|=\sqrt{\sum_{i=1}^{n}\left(u_{i j}^{q}\right)^{2}},\left\|1 / u_{i j}^{q}\right\|=\sqrt{\sum_{i=1}^{n}\left(1 / u_{i j}^{q}\right)^{2}}$.

The standardized formula can be expressed as follows:

$$
\left\{\begin{aligned}
x_{i j}^{q L} & =\frac{u_{i j}^{q L}}{\sqrt{\sum_{i=1}^{n}\left(u_{i j}^{q L}\right)^{2}}} \\
x_{i j}^{q M} & =\frac{u_{i j}^{q M}}{\sqrt{\sum_{i=1}^{n}\left(u_{i j}^{q M}\right)^{2}}}, j \in I_{1}, i \in N \\
x_{i j}^{q U} & =\frac{u_{i j}^{q u}}{\sqrt{\sum_{i=1}^{n}\left(u_{i j}^{q L}\right)^{2}}}
\end{aligned}\right.
$$

or

$$
\left\{\begin{aligned}
x_{i j .}^{q L} & =\frac{1 / u_{i j L}^{q}}{\sqrt{\sum_{i=1}^{n}\left(1 / u_{i j U}^{q}\right)^{2}}} \\
x_{i j}^{q M} & =\frac{1 / u_{i j M}^{q}}{\sqrt{\sum_{i=1}^{n}\left(1 / u_{i j M}^{q}\right)^{2}}}, j \in I_{2}, i \in N \\
x_{i j}^{q U} & =\frac{1 / u_{i j U}^{q}}{\sqrt{\sum_{i=1}^{n}\left(1 / u_{i j L}^{q}\right)^{2}}}
\end{aligned}\right.
$$

(4) Integrate attribute values for alternatives

$\widetilde{R}_{i j}^{q}=\left(\widetilde{r}_{i j}^{q}\right)_{n \times m}$ is the $j$ th attribute value matrix of the $i$ th scheme,

$$
\widetilde{r}_{i j}^{q}=\sum_{i=1}^{n} \sum_{j=1}^{m} \widetilde{x}_{i j}^{q} \times \widetilde{w}_{j}^{q} \times e_{i j}^{q}
$$

(5) Define the Fuzzy Positive Ideal Solution $S^{q+}$ and the Fuzzy Negative Ideal Solution 
$\widetilde{r}_{j}^{q+}$ represents the positive ideal value of the $j$ th fuzzy attribute value in the $n$ schemes. $\widetilde{r}_{j}^{q-}$ represents the negative ideal value of the $j$ th fuzzy attribute value in the $n$ schemes [48].

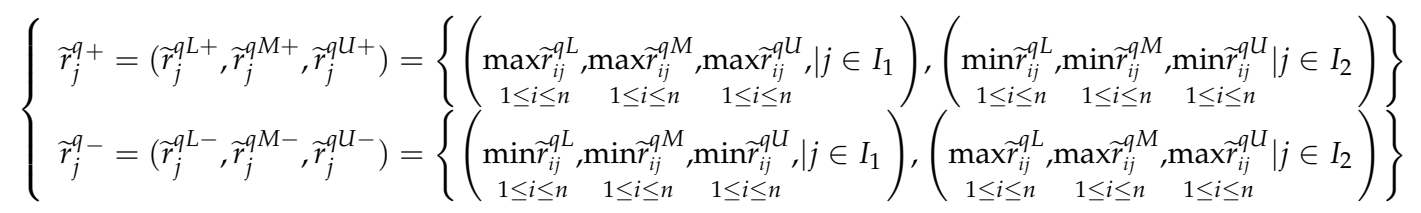

The positive ideal solution is:

$$
R^{q+}=\left(\widetilde{r}_{1}^{q+}, \ldots \widetilde{r}_{m}^{q+}\right)
$$

The negative ideal solution is:

$$
R^{q-}=\left(\widetilde{r}_{1}^{q-}, \ldots \widetilde{r}_{m}^{q-}\right)
$$

(6) Compute the distances $d_{i}^{q+}$ and $d_{i}^{q-}$ of each alternative according to Equations (4) and (5).

$$
\begin{aligned}
& d_{i}^{q+}=\sqrt{d_{\left(\widetilde{r}_{i 1}^{q}, \widetilde{r}_{1}^{q+},\right)}^{+d^{2}}\left(\widetilde{r}_{i 2^{\prime}}^{q} \widetilde{r}_{2}^{q+},\right)+\ldots \ldots d^{2}\left(\widetilde{r}_{i m^{\prime}}^{q} \widetilde{r}_{m}^{q+},\right)} \\
& d_{i}^{q-}=\sqrt{\left.\left.\left.d_{\left(\widetilde{r}_{i 1}^{q},\right.} \widetilde{r}_{1}^{q-},\right)+d_{\left(\widetilde{r}_{i 2}^{\prime}\right.}^{2} \widetilde{r}_{2}^{q-},\right)+\ldots \ldots d^{2} \widetilde{r}_{i m^{\prime}}^{q} \widetilde{r}_{m}^{q-},\right)}
\end{aligned}
$$

The relative proximity of the $q$ th decision maker in the $i$ th scheme:

$$
C_{i}^{q}=\frac{d_{i}^{q+}}{d_{i}^{q+}+d_{i}^{q-}}
$$

Get the relative closeness matrix of group decision making: $C=\left[\begin{array}{cccc}C_{1}^{1} & C_{1}^{2} & \cdots & C_{1}^{L} \\ C_{2}^{1} & C_{2}^{2} & \cdots & C_{2}^{L} \\ \vdots & \vdots & \cdots & \vdots \\ C_{n}^{1} & C_{n}^{2} & \cdots & C_{n}^{L}\end{array}\right]$

(7) Calculate comprehensive closeness

The group relative closeness degree $S_{i}^{*}$ is synthesized

$$
S_{i}^{*}=\sum_{q=1}^{L} \lambda^{q} \times C_{i}^{q}
$$

Finally, the advantages and disadvantages of the scheme are compared according to the numerical values of $S_{i}^{*}$. The greater the value of $S_{i}^{*}$, the better the scheme.

\section{Example Analysis}

$t$ is assumed that there are four evacuation plans $\left(X_{1}, X_{2}, X_{3}, X_{4}\right)$ at the Fukushima nuclear accident and four experts have evaluated the evacuation plan from seven aspects, namely, emergency planning area size $\left(G_{1}\right)$, evacuation demand $\left(G_{2}\right)$, road traffic $\left(G_{3}\right)$, unfavorable weather conditions $\left(G_{4}\right)$, traffic capacity $\left(G_{5}\right)$, the time spent before leaving and running time $\left(G_{6}\right)$, and reverse road(s) of the power plant $\left(G_{7}\right)$. The weights of the experts are $\lambda^{1}=0.4, \quad \lambda^{2}=0.1, \quad \lambda^{3}=0.3, \quad \lambda^{4}=0.2$. The four experts use triangular fuzzy numbers to represent the evaluation values, which are shown in Table 2 .

$$
\begin{aligned}
& \widetilde{w}_{j}^{1}=\left(\begin{array}{lllllll}
(0,0.25,0.5) & (0.25,0.5,0.75) & (0,0.25,0.5) & (0.25,0.5,0.75) & (0.5,0.75,1) & (0.75,1,1) & (0,0,0.25)
\end{array}\right) \\
& \widetilde{w}_{j}^{2}=\left(\begin{array}{lllllll}
(0.5,0.75,1) & (0,0.25,0.5) & (0.25,0.5,0.75) & (0,0.25,0.5) & (0.5,0.75,1) & (0,0.25,0.5) & (0,0.25,0.5)
\end{array}\right)
\end{aligned}
$$

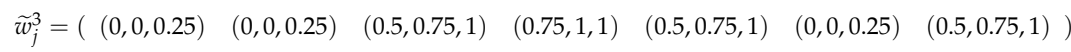

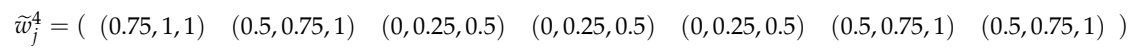


Table 2. The evaluation values of evacuation schemes.

\begin{tabular}{|c|c|c|c|c|c|c|c|c|}
\hline $\begin{array}{c}\text { Decision } \\
\text { Maker }\end{array}$ & Schemes & $\mathrm{G}_{1}$ & $\mathrm{G}_{2}$ & $\mathrm{G}_{3}$ & $\mathrm{G}_{4}$ & $\mathrm{G}_{5}$ & $\mathrm{G}_{6}$ & $\mathrm{G}_{7}$ \\
\hline \multirow{4}{*}{$D_{1}$} & $X_{1}$ & $(0,0,0.25)$ & $(0,0.25,0.5)$ & $(0.5,0.75,1)$ & $(0.75,1,1)$ & $(0,0,0.25)$ & $(0.25,0.5,0.75)$ & $(0.25,0.5,0.75)$ \\
\hline & $x_{2}$ & $(0,0.25,0.5)$ & $(0,0,0.25)$ & $(0.75,1,1)$ & $(0.25,0.5,0.75)$ & $(0,0,0.25)$ & $(0.5,0.75,1)$ & $(0.5,0.75,1)$ \\
\hline & $x_{3}$ & $(0,0,0.25)$ & $(0,0,0.25)$ & $(0,0,0.25)$ & $(0.5,0.75,1)$ & $(0,0,0.25)$ & $(0,0,0.25)$ & $(0,0,0.25)$ \\
\hline & $X_{4}$ & $(0,0,0.25)$ & $(0.5,0.75,1)$ & $(0,0,0.25)$ & $(0.25,0.5,0.75)$ & $(0.75,1,1)$ & $(0,0,0.25)$ & $(0,0.25,0.5)$ \\
\hline \multirow{4}{*}{$D_{2}$} & $x_{1}$ & $(0.25,0.5,0.75)$ & $(0.5,0.75,1)$ & $(0.25,0.5,0.75)$ & $(0,0,0.25)$ & $(0,0,0.25)$ & $(0.5,0.75,1)$ & $(0.5,0.75,1)$ \\
\hline & $x_{2}$ & $(0,0.25,0.5)$ & $(0.5,0.75,1)$ & $(0,0.25,0.5)$ & $(0.5,0.75,1)$ & $(0.75,1,1)$ & $(0.5,0.75,1)$ & $(0,0,0.25)$ \\
\hline & $x_{3}$ & $(0.25,0.5,0.75)$ & $(0,0.25,0.5)$ & $(0.5,0.75,1)$ & $(0.5,0.75,1)$ & $(0.5,0.75,1)$ & $(0.5,0.75,1)$ & $(0.75,1,1)$ \\
\hline & $\mathrm{X}_{4}$ & $(0,0,0.25)$ & $(0,0,0.25)$ & $(0.5,0.75,1)$ & $(0,0,0.25)$ & $(0.25,0.5,0.75)$ & $(0,0,0.25)$ & $(0,0.25,0.5)$ \\
\hline \multirow{4}{*}{$D_{3}$} & $x_{1}$ & $(0.5,0.75,1)$ & $(0.25,0.5,0.75)$ & $(0,0,0.25)$ & $(0.75,1,1)$ & $(0,0,0.25)$ & $(0,0,0.25)$ & $(0,0.25,0.5)$ \\
\hline & $x_{2}$ & $(0.75,1,1)$ & $(0.5,0.75,1)$ & $(0,0,0.25)$ & $(0.5,0.75,1)$ & $(0,0.25,0.5)$ & $(0.5,0.75,1)$ & $(0,0.25,0.5)$ \\
\hline & $x_{3}$ & $(0.5,0.75,1)$ & $(0,0.25,0.5)$ & $(0.5,0.75,1)$ & $(0.5,0.75,1)$ & $(0.75,1,1)$ & $(0.5,0.75,1)$ & $(0.5,0.75,1)$ \\
\hline & $x_{4}$ & $(0.5,0.75,1)$ & $(0,0,0.25)$ & $(0.5,0.75,1)$ & $(0,0.25,0.5)$ & $(0.75,1,1)$ & $(0,0.25,0.5)$ & $(0.75,1,1)$ \\
\hline \multirow{4}{*}{$D_{4}$} & $x_{1}$ & $(0.5,0.75,1)$ & $(0.75,1,1)$ & $(0,0,0.25)$ & $(0,0.25,0.5)$ & $(0.5,0.75,1)$ & $(0.75,1,1)$ & $(0,0.25,0.5)$ \\
\hline & $x_{2}$ & $(0.5,0.75,1)$ & $(0.5,0.75,1)$ & $(0.5,0.75,1)$ & $(0,0,0.25)$ & $(0.5,0.75,1)$ & $(0,0,0.25)$ & $(0,0,0.25)$ \\
\hline & $x_{3}$ & $(0.5,0.75,1)$ & $(0.75,1,1)$ & $(0,0,0.25)$ & $(0,0.25,0.5)$ & $(0.5,0.75,1)$ & $(0.5,0.75,1)$ & $(0,0,0.25)$ \\
\hline & $\mathrm{X}_{4}$ & $(0.5,0.75,1)$ & $(0,0,0.25)$ & $(0.5,0.75,1)$ & $(0,0,0.25)$ & $(0,0,0.25)$ & $(0.5,0.75,1)$ & $(0,0,0.25)$ \\
\hline
\end{tabular}


Step 1: Normalization of attribute values in Table 1 according to the Equations (1) and (2).

Step 2: The relative importance of experts can be divided into two categories $(K=2)$ based on professional background, working years, and work nature. The experts' weights according to each scheme's attributes have been calculated by using the Matlab program according to the clustering language in the K-means method. Finally, the weight of the four decision makers $D_{1}, D_{2}, D_{3}$, and $D_{4}$ are shown in Table 3.

Table 3. Experts' weights according to each scheme's attributes.

\begin{tabular}{ccccccccc}
\hline $\begin{array}{c}\text { Decision } \\
\text { Maker }\end{array}$ & Schemes & $\mathrm{G}_{\mathbf{1}}$ & $\mathrm{G}_{\mathbf{2}}$ & $\mathrm{G}_{\mathbf{3}}$ & $\mathrm{G}_{\mathbf{4}}$ & $\mathrm{G}_{\mathbf{5}}$ & $\mathrm{G}_{\mathbf{6}}$ & $\mathrm{G}_{\mathbf{7}}$ \\
\hline \multirow{3}{*}{$D_{1}$} & $\mathrm{X}_{1}$ & $1 / 4$ & $1 / 2$ & $3 / 4$ & $1 / 2$ & $3 / 4$ & $1 / 4$ & $3 / 4$ \\
& $\mathrm{X}_{2}$ & $3 / 4$ & $1 / 2$ & $1 / 4$ & $1 / 2$ & $1 / 4$ & $3 / 4$ & $1 / 4$ \\
& $\mathrm{X}_{3}$ & $3 / 4$ & $1 / 2$ & $3 / 4$ & $1 / 2$ & $3 / 4$ & $3 / 4$ & $3 / 4$ \\
& $\mathrm{X}_{4}$ & $3 / 4$ & $1 / 2$ & $3 / 4$ & $1 / 2$ & $3 / 4$ & $3 / 4$ & $3 / 4$ \\
\hline \multirow{5}{*}{$D_{2}$} & $\mathrm{X}_{1}$ & $3 / 4$ & $1 / 4$ & $3 / 4$ & $3 / 4$ & $1 / 2$ & $3 / 4$ & $1 / 2$ \\
& $\mathrm{X}_{2}$ & $1 / 4$ & $3 / 4$ & $1 / 4$ & $1 / 4$ & $1 / 2$ & $1 / 4$ & $1 / 2$ \\
& $\mathrm{X}_{3}$ & $3 / 4$ & $3 / 4$ & $3 / 4$ & $3 / 4$ & $1 / 2$ & $3 / 4$ & $1 / 2$ \\
& $\mathrm{X}_{4}$ & $3 / 4$ & $3 / 4$ & $3 / 4$ & $3 / 4$ & $1 / 2$ & $3 / 4$ & $1 / 2$ \\
\hline \multirow{2}{*}{$D_{3}$} & $\mathrm{X}_{1}$ & $3 / 4$ & $3 / 4$ & $1 / 4$ & $1 / 2$ & $1 / 2$ & $3 / 4$ & $1 / 4$ \\
& $\mathrm{X}_{2}$ & $3 / 4$ & $1 / 4$ & $3 / 4$ & $1 / 2$ & $1 / 2$ & $3 / 4$ & $3 / 4$ \\
& $\mathrm{X}_{3}$ & $3 / 4$ & $3 / 4$ & $3 / 4$ & $1 / 2$ & $1 / 2$ & $3 / 4$ & $3 / 4$ \\
& $\mathrm{X}_{4}$ & $1 / 4$ & $3 / 4$ & $3 / 4$ & $1 / 2$ & $1 / 2$ & $1 / 4$ & $3 / 4$ \\
\hline \multirow{2}{*}{$D_{4}$} & $\mathrm{X}_{1}$ & $1 / 2$ & $3 / 4$ & $1 / 4$ & $3 / 4$ & $1 / 4$ & $1 / 2$ & $3 / 4$ \\
& $\mathrm{X}_{2}$ & $1 / 2$ & $1 / 4$ & $3 / 4$ & $3 / 4$ & $3 / 4$ & $1 / 2$ & $1 / 4$ \\
& $\mathrm{X}_{3}$ & $1 / 2$ & $3 / 4$ & $3 / 4$ & $3 / 4$ & $3 / 4$ & $1 / 2$ & $3 / 4$ \\
& $\mathrm{X}_{4}$ & $1 / 2$ & $3 / 4$ & $3 / 4$ & $1 / 4$ & $3 / 4$ & $1 / 2$ & $3 / 4$ \\
\hline
\end{tabular}

Step 3: Integrate attribute values for alternatives according to Equation (3).

$$
\begin{gathered}
\widetilde{R}_{1 j}^{q}=\left[\begin{array}{lllllll}
(0.01,0.11,1.13) & (0,0.05,0.5) & (0.09,0.27,0.92) & (0.09,0.24,0.46) & (0,0,0.08) & (0.35,0.64,1.23) & (0.63,1,1.79) \\
(0,0.17,2.25) & (0,0.15,1) & (0.05,0.12,0.31) & (0.06,0.18,0.46) & (0,0,0.03) & (0.24,0.48,1.23) & (0.13,1,2.38) \\
(0.03,0.33,3.38) & (0,0,0.25) & (0,0,0.23) & (0.06,0.18,0.46) & (0,0,0.08) & (0.24,0.48,0.91) & (0.06,0.42,0.89) \\
(0,0,1.12) & (0,0,0.25) & (0,0,0.23) & (0,0,0.12) & (0,0,0.34) & (0.16,0.36,0.91) & (0.16,1.87,4.53)
\end{array}\right] \\
\widetilde{R}_{2 j}^{q}=\left[\begin{array}{cccccccc}
(0,0.13,3.13) & (0.03,0.12,0.5) & (0.02,0.13,0.1) & (0,0,0.62) & (0,0,0.07) & (0.27,0.84,5.12) & (0.14,0.56,1.92) \\
(0,0.04,1.04) & (0.08,0.35,1.5) & (0,0,0.05) & (0.03,0.16,0.83) & (0,0.07,0.29) & (0.16,0.36,0.91) & (0.22,0.63,2) \\
(0,0.25,4.69) & (0,0.12,0.75) & (0.05,0.21,0.56) & (0,0,0.62) & (0,0.05,0.29) & (0.36,1.21,4) & (0.19,0.85,3.33) \\
(0,0.15,0.6) & (0,0,0.38) & (0.05,0.21,0.56) & (0,0,0.62) & (0,0.04,0.22) & (0.17,0.89,6.00) & (0.29,0.56,1.14)
\end{array}\right] \\
\widetilde{R}_{3 j}^{q}=\left[\begin{array}{cccccccc}
(0.05,0.16,0.57) & (0.02,0.12,0.6) & (0,0,0.1) & (0.09,0.23,0.47) & (0,0,0.03) & (0.27,0.86,3.19) & (0.13,0.28,0.76) \\
(0.07,0.21,0.57) & (0.1,0.48,2.4) & (0,0,0.1) & (0.06,0.17,0.47) & (0,0,0.05) & (0.24,0.67,2) & (0.27,0.86,3.19) \\
(0.05,0.16,0.57) & (0,0.16,1.2) & (0,0,0.38) & (0.09,0.17,0.47) & (0,0,0.11) & (0.15,0.34,0.94) & (0.24,0.67,2) \\
(0.02,0.05,0.19) & (0,0,0.6) & (0,0,0.16) & (0,0.05,0.24) & (0,0,0.11) & (0.33,0.49,0.89) & (0.15,0.34,0.94)
\end{array}\right] \\
\widetilde{R}_{4 j}^{q}=\left[\begin{array}{cccccccc}
(0.04,0.17,0.67) & (0.09,0.32,0.44) & (0,0,0.13) & (0,0.2,1.5) & (0,0.04,0.25) & (0.24,0.67,2) & (0,0.14,0.45) \\
(0.04,0.17,0.67) & (0.03,0.06,0.15) & (0.14,0.5,1.5) & (0,0.2,1.5) & (0,0.13,0.75) & (0.32,1.09,4) & (0.13,0.26,0.85) \\
(0,0,0.17) & (0.09,0.32,0.44) & (0,0,0.39) & (0,0,0.75) & (0,0,0.19) & (0.16,0.44,1.33) & (0.18,0.55,1.15) \\
(0.04,0.17,0.67) & (0,0,0.11) & (0.14,0.5,1.5) & (0.04,0.2,1) & (0,0,0.19) & (0,0,1.08) & (0.01,0.16,0.98)
\end{array}\right]
\end{gathered}
$$

Step 4: Determine positive and negative ideals according to Equation (4).

$$
\begin{gathered}
\left\{\begin{array}{r}
\widetilde{R}^{1+}=\left[\begin{array}{lllllll}
(0.03,0.33,3.38) & (0,0.15,1) & (0.09,0.27,0.92) & (0.09,0.24,0.46) & (0,0,0.34) & (0.35,0.64,1.23) & (0.63,1.87,4.53)
\end{array}\right] \\
\widetilde{R}^{1-}=\left[\begin{array}{lllllll}
(0,0,1.12) & (0,0,0.25) & (0,0,0.23) & (0,0,0.12) & (0,0,0.03) & (0.16,0.36,1.23) & (0.06,0.42,0.89)
\end{array}\right]
\end{array}\right. \\
\left\{\begin{array}{r}
\widetilde{R}^{2+}=\left[\begin{array}{lllllll}
(0,0.25,4.69) & (0.08,0.35,1.5) & (0.05,0.21,0.56) & (0.03,0.16,0.83) & (0,0.07,0.29) & (0.36,1.21,6) & (0.29,0.85,3.33)
\end{array}\right] \\
\widetilde{R}^{2-}=\left[\begin{array}{lllllll}
(0,0.04,0.6) & (0,0,0.38) & (0,0,0.05) & (0,0,0.62) & (0,0,0.07) & (0.16,0.36,0.91) & (0.14,0.56,1.14)
\end{array}\right]
\end{array}\right. \\
\left\{\begin{array}{c}
\widetilde{R}^{3+}=\left[\begin{array}{lllllll}
(0.07,0.21,0.57) & (0.1,0.48,2.4) & (0,0,0.38) & (0.09,0.23,0.47) & (0,0,0.11) & (0.33,0.86,3.19) & (0.27,0.86,3.19)
\end{array}\right] \\
\widetilde{R}^{3-}=\left[\begin{array}{lllllll}
(0.02,0.05,0.19) & (0,0,0.6) & (0,0,0.1) & (0,0.05,0.24) & (0,0,0.03) & (0.15,0.34,0.94) & (0.13,0.28,0.76)
\end{array}\right]
\end{array}\right.
\end{gathered}
$$




$$
\left\{\begin{array}{c}
\widetilde{R}^{4+}=\left[\begin{array}{ccccccc}
(0.04,0.17,0.67) & (0.09,0.32,0.44) & (0.14,0.5,1.5) & (0.04,0.2,1.5) & (0,0.13,0.75) & (0.32,1.09,4) & (0.18,1.55,1.15)
\end{array}\right] \\
\widetilde{R}^{4-}=\left[\begin{array}{lllllll}
(0,0,0.17) & (0,0,0.11) & (0,0,0.39) & (0,0,0.75) & (0,0,0.19) & (0,0,1.08) & (0,0.14,0.45)
\end{array}\right]
\end{array}\right.
$$

Step 5: The relative closeness degree of the group is calculated according to Equations (5)-(7), the matrix is obtained as follows:

$$
C=\left(C_{i}^{q}\right)_{4 \times 4}=\left[\begin{array}{llll}
0.41 & 0.68 & 0.56 & 0.72 \\
0.24 & 0.57 & 0.81 & 0.53 \\
0.53 & 0.47 & 0.45 & 0.47 \\
0.35 & 0.86 & 0.63 & 0.69
\end{array}\right]
$$

Step 6: The relative closeness degree of population synthesis is calculated according to Equation (8), the results are as follows:

$$
S_{1}^{*}=0.544 \quad S_{2}^{*}=0.502 \quad S_{3}^{*}=0.488 \quad S_{4}^{*}=0.553
$$

According to the comprehensive closeness degree, the order of the four decision schemes is as follows: $S_{4}^{*}>S_{1}^{*}>S_{2}^{*}>S_{3}^{*}$.

\section{Discussion and Conclusions}

This paper has studied how a commander faced with an uncertain environment effectively integrates experts' opinions to make the best transient evacuation decision in a nuclear accident. After theoretical analysis and the consideration of a case study, this paper has drawn the following conclusions: (1) Based on the existing theory, this paper constructs a decision index system that includes seven indicators, such as the size of the emergency plan area, evacuation demand, road traffic road, adverse meteorological conditions, traffic capacity, the time spent before leaving and running time, and the reverse road(s) of the power plant. Triangular fuzzy language is one of the methods used to describe the attributes of programs with incomplete information; (2) When the commander does not fully understand the importance of experts, the K-means clustering method can be used to calculate the weight of the decision makers under different attributes in an nuclear accident, which reduces the influence of subjective factors of the decision makers; (3) A nuclear accident emergency evacuation is a multi-attribute decision problem, and the Fuzzy-TOPSIS method, which is a simple and effective decision-making method, can be taken into consideration to select the optimal emergency program. This paper mainly sets up the simulation of a nuclear accident emergency evacuation decision scenario as a situation that is subjected to incomplete information. It eliminates the influence of subjective factors of decision makers to a certain extent, but the model is not suitable for a scenario where all parameter information disappears. The next step is to combine the exact number, interval number, and triangular fuzzy number to describe the nuclear accident emergency scenario more concretely and construct a more comprehensive and reliable decision system.

Nuclear accident emergency decision making is one of the core issues to be solved in nuclear power development. A lack of nuclear accidents in the past does not mean that nuclear accidents will not occur in our country's nuclear industry in the future. Once a nuclear accident occurs, the psychology and living environment of people will change greatly. In an uncertain environment, using a decision-making model based on fuzzy language can provide an important reference value for making an emergency evacuation decision following a nuclear accident. However, how to further quantify the evaluation indicators in decision-making is a meaningful question.

Author Contributions: Conceptualization: S.Z., D.Y.; Methodology, Software, Data, Writing-Original Draft Preparation: Y.D.; Writing-Review and Editing: S.Z., D.Y.

Funding: Hunan Science and Technology Major Project (2012FJ1007), The National Natural Science Foundation of China (No. 71573283).

Conflicts of Interest: The authors declare no conflict of interest. 


\section{References}

1. Ashley, S.F.; Vaughan, G.J.; Nuttall, W.J.; Thomasb, P.J. Considerations in relation to off-site emergency procedures and response for nuclear accidents. Process Saf. Environ. Prot. 2017, 112, 77-95. [CrossRef]

2. Ashley, S.F.; Vaughan, G.J.; Nuttall, W.J.; Thomas, P.J.; Higgins, N.A. Predicting the cost of the consequences of a large nuclear accident in the UK. Process Saf. Environ. Prot. 2017, 112, 96-113. [CrossRef]

3. Crichton, M.T.; Flin, R.; Mcgeorge, P. Decision making by on-scene incident commanders in nuclear emergencies. Cogn. Technol. Work 2005, 7, 156-166. [CrossRef]

4. Thomas, P.J. Quantitative guidance on how best to respond to a big nuclear accident. Process Saf. Environ. Prot. 2017, 112, 4-15. [CrossRef]

5. Waddington, I.; Thomas, P.J.; Taylor, R.H.; Vaughan, G.J. J-value assessment of relocation measures following the nuclear power plant accidents at Chernobyl and Fukushima Daiichi. Process Saf. Environ. Prot. 2017, 112, 16-49. [CrossRef]

6. Protective Action Guides and Planning Guidance for Radiological Incidents; No. EPA-HQ-OAR-2007-0268; U.S. Environmental Protection Agency: Washington, DC, USA, 2013.

7. IAEA. Lessons Learned from the Response to Radiation Emergencies (1945-2010); IAEA Safety Standards; IAEA: Vienna, Austria, 2012.

8. Liu, L. Decision Methods for Nuclear Accident Emergencies. Nuclear Power Eng. 2001, 22, $267-271$.

9. Xu, Z.; Xi, S.; Qu, J. Multi-attribute analysis of nuclear reactor accident emergency decision making. J. Tsinghua Univ. 2008, 48, 445-448.

10. Dash, N.; Gladwin, H. Evacuation decision making and behavioral responses: Individual and household. Nat. Hazards Rev. 2007, 8, 69-77. [CrossRef]

11. Emel'yanov, I.Y.; Kuznetsov, S.P.; Cherkashov, Y.M. Design provisions for operational capability of a nuclear power plant with a high-powered water-cooled channel reactor in emergency regimes. Sov. At. Energy 1981, 50, 226-230. [CrossRef]

12. Urbanik, T.; Desrosiers, A.; Lindell, M.K.; Schuller, C.R. Analysis of Techniques for Estimating Evacuation Times for Emergency Planning Zones; Texas Transportation Institute: Seattle, WA, USA, 1980.

13. Moeller, M.P.; Urbanik, I.I.; Desrosiers, A.E. CLEAR (Calculates Logical Evacuation and Response): A Generic Transportation Network Model for the Calculation of Evacuation Time Estimates; Pacific Northwest National Lab (PNNL): Richland, WA, USA, 1982.

14. Tseng, C.C.; Chang, N.B. Environmental Exposure Assessment for Emergency Response in a Nuclear Power Plant Using an Integrated Source Term and 3D Numerical Model. Environ. Model. Assess. 2009, $14,661$. [CrossRef]

15. Srinivas, C.V.; Rakesh, P.T.; Baskaran, R.; Venkatraman, B. Source term assessment using inverse modeling and environmental radiation measurements for nuclear emergency response. Air Qual. Atmos. Health 2017, 10, 1-11. [CrossRef]

16. Silva, C.; Pimentel, L.C.; Landau, L.; Heilbron Filho, P.F.; Gobbo, F.G.; de Sousa, P.D. Supportive elements to the decision-making process in the emergency planning of the Angra dos Reis Nuclear Power Complex, Brazil. Environ. Earth Sci. 2017, 76, 133. [CrossRef]

17. Wang, H.F.; Engineer, S. Study on Emergency Evacuation for Nuclear Power Plants. China Saf. Sci. J. 2010, 20, 26-31.

18. Halkos, G.E.; Tzeremes, N.G. Industry performance evaluation with the use of financial ratios: An application of bootstrapped DEA. Expert Syst. Appl. 2012, 39, 5872-5880. [CrossRef]

19. Gao, Y.; Zhang, L.; Zhou, D. Performance evaluation of coal enterprises energy conservation and reduction of pollutant emissions base on GRD-TOPSIS. Energy Procedia 2011, 5, 535-539.

20. Safaei Ghadikolaei, A.; Khalili Esbouei, S.; Antucheviciene, J. Applying fuzzy MCDM for financial performance evaluation of Iranian companies. Technol. Econ. Dev. Econ. 2014, 20, 274-291. [CrossRef]

21. Chakraborty, S.; Paul, D.; Agarwal, P.K. Evaluation of educational performance of Indian states using PROMETHEE-GIS approach. Benchmarking 2017, 24, 1709-1728. [CrossRef]

22. Hoseinpour, M.; Sadrnia, H.; Tabasizadeh, M.; Ghobadian, B. Evaluation of the effect of gasoline fumigation on performance and emission characteristics of a diesel engine fueled with B20 using an experimental investigation and TOPSIS method. Fuel 2018, 223, 277-285. [CrossRef] 
23. Govindan, K.; Khodaverdi, R.; Jafarian, A. A fuzzy multi criteria approach for measuring sustainability performance of a supplier based on triple bottom line approach. J. Clean. Prod. 2013, 47, 345-354. [CrossRef]

24. Samanlioglu, F.; Taskaya, Y.E.; Gulen, U.C.; Cokcan, O. A Fuzzy AHP-TOPSIS-Based Group Decision-Making Approach to IT Personnel Selection. Int. J. Fuzzy Syst. 2018, 20, 1576-1591. [CrossRef]

25. Jia, X.; Morel, G.; Martell-Flore, H.; Hissel, F.; Batoz, J.-L. Fuzzy logic based decision support for mass evacuations of cities prone to coastal or river floods. Environ. Modell. Softw. 2016, 85, 1-10. [CrossRef]

26. Hammond, G.D.; Bier, V.M. Alternative evacuation Strategies for nuclear power Accidents. Reliab. Eng. Syst. Saf. 2014, 135, 9-14. [CrossRef]

27. Malešič, M.; Prezelj, I.; Juvan, J.; Polič, M.; Uhan, S. Evacuation in the event of a nuclear disaster: Planned activity or improvisation? Int. J. Disaster Risk Reduct. 2015, 12, 102-111. [CrossRef]

28. Zadeh, L.A. Outline of a new approach to the analysis of complex systems and decision processes. IEEE Trans. Syst. Man Cybernet. 1973, 3, 28-44. [CrossRef]

29. Bier, V.M. Is fuzzy set theory more general than probability theory? In Proceedings of the International Symposium on Uncertainty Modeling and Analysis, College Park, MD, USA, 3-5 December 1990; pp. 297-301.

30. Chai, J.; Liu, J.N.K.; Ngai, E.W.T. Application of decision-making techniques in sup- plier selection: A systematic review of literature. Expert Syst. Appl. 2013, 40, 3872-3885. [CrossRef]

31. Xin, J. Optimization of nuclear accident emergency decision making scheme based on interval analytic hierarchy process. Radiat. Prot. 2007, 27, 282-285.

32. Boran, F.E.; Genç, S.; Kurt, M.; Akay, D. A multi-criteria intuitionistic fuzzy group decision making for supplier selection with TOPSIS method. Expert Syst. Appl. 2009, 36, 11363-11368. [CrossRef]

33. Wu, Z.; Chen, Y. The maximizing deviation method for group multiple attribute decision making under linguistic environment. Fuzzy Sets Syst. 2007, 158, 1608-1617. [CrossRef]

34. Onu, P.U.; Quan, X.; Xu, L.; Orji, J.; Onu, E. Evaluation of sustainable acid rain control options utilizing a fuzzy TOPSIS multi-criteria decision analysis model frame work. J. Clean. Prod. 2017, 141, 612-625. [CrossRef]

35. Liu, J.; Wei, Q. Risk evaluation of electric vehicle charging infrastructure public-private partnership projects in China using fuzzy TOPSIS. J. Clean. Product. 2018, 189, 211-222. [CrossRef]

36. Han, H.; Trimi, S. A Fuzzy TOPSIS Method for Performance Evaluation of Reverse Logistics in Social Commerce Platforms. Expert Syst. Appl. 2018, 103, 133-145. [CrossRef]

37. Wu, C.; Liu, G.; Huang, C.; Liu, Q.; Guan, X. Ecological Vulnerability Assessment Based on Fuzzy Analytical Method and Analytic Hierarchy Process in Yellow River Delta. Int. J. Environ. Res. Public Health 2018, 15, 855. [CrossRef] [PubMed]

38. Li, B.; Wang, J.; Li, W. The establishment of innovative enterprise human capital value evaluation indicators system based on grounded theory method-statistical method-information entropy. J. Discret. Math. Sci. Cryptogr. 2018, 21, 577-582. [CrossRef]

39. Huang, Z. Extensions to the k-means algorithm for clustering large data sets with categorical values. Data Min. Knowl. Discov. 1998, 2, 283-304. [CrossRef]

40. Li, M.J.; Ng, M.K.; Cheung, Y.; Huang, J.Z. Agglomerative fuzzy k-means clustering algorithm with selection of number of clusters. IEEE Trans. Knowl. Data Eng. 2008, 20, 1519-1534. [CrossRef]

41. Ray, S.; Turi, R.H. Determination of Number of Clusters in K-Means Clustering and Application in Colour Image Segmentation. In Proceedings of the 4th International Conference on Advances in Pattern Recognition and Digital Techniques, Calcutta, India, 27-29 December 1999.

42. Wang, L.M.; Shao, Y.M. Crack Fault Classification for Planetary Gearbox Based on Feature Selection Technique and K-means Clustering Method. Chin. J. Mech. Eng. 2018, 31, 4. [CrossRef]

43. Desarbo, W.S.; Carroll, J.D.; Clark, L.A.; Green, P.E. Synthesized Clustering: A Method for Amalgamating Clustering Bases with Differential Weighting Variables. Psychometrika 1984, 49, 57-78. [CrossRef]

44. De Soete, G. OVWTRE: A Program for Optimal Variable Weighting for Ultrametric and Additive Tree Fitting. J. Classif. 1988, 5, 101-104. [CrossRef]

45. Dotson, L.J.; Jones, J.A. Development of Evacuation Time Estimate Studies for Nuclear Power Plants; Division of Preparedness and Response, Office of Nuclear Security and Incident Response, US Nuclear Regulatory Commission: Washington, DC, USA, 2005. 
46. Li, D.F. A note on "using intuitionistic fuzzy sets for fault-tree analysis on printed circuit board assembly". Microelectron. Reliab. 2008, 48, 1741. [CrossRef]

47. Qiao, P.; Shi, L.; Fu, L. A Supplier Evaluation Based on the Closeness Degree of Triangular Fuzzy Number Research. In Proceedings of the Seventh International Symposium on Computational Intelligence and Design, Hangzhou, China, 13-14 December 2015; pp. 441-444.

48. Xu, X.; Huang, Z.; Chen, X. A conflict eliminating coordination method for emergency decision of unexpected incidents. In Proceedings of the Sixth International Conference on Management Science and Engineering Management; Springer: London, UK, 2013; pp. 295-307.

49. Lu, Y.; Weng, C. Research on the clustering algorithm of uncertain data based on triangular fuzzy number. J. Zhejiang Univ. Technol. 2016, 44, 406-409.

50. Xu, Z. Study on Method for Triangular Fuzzy Number-Based Multi-Attribute Decision Making with Preference Information on Alternatives. Syst. Eng. Electron. 2002, 24, 9-13.

51. Wan, S.P.; Dong, J.Y. Multi-attribute Decision Making based on Triangular Intuitionistic Fuzzy Number Choquet Integral Operator. Chin. Manag. Sci. 2014, 22, 122-125.

(C) 2018 by the authors. Licensee MDPI, Basel, Switzerland. This article is an open access article distributed under the terms and conditions of the Creative Commons Attribution (CC BY) license (http://creativecommons.org/licenses/by/4.0/). 